\title{
Mecanismos Patogênicos da Doença Periodontal Associada ao Diabetes Melito
}

\section{revisão}

\author{
CrÉsIO AlVES \\ JULIANA ANDION \\ MÁRCIA BRANDÃO \\ RAFAela Menezes
}

Faculdade de Medicina, Universidade Federal da Bahia,

Salvador, BA.
Recebido em 19/12/06 Aceito em 04/04/07

\section{RESUMO}

Objetivo: Revisão sistemática do conhecimento atual sobre a associação entre diabetes melito (DM) e doença periodontal (DP) com ênfase na sua fisiopatogenia. Fonte de dados: Pesquisa bibliográfica, nos últimos cinco anos, através dos bancos de dados MEDLINE e LILACS, usando as palavras-chaves "diabetes mellitus", "periodontal disease" e "periodontitis". Síntese dos dados: Os tecidos periodontais são as estruturas bucais mais afetadas pelo DM. O DM predispõe ao desenvolvimento da DP, a qual leva ao descontrole glicêmico, o que ressalta a importância da relação bidirecional entre essas duas doenças. Vários mecanismos estão envolvidos na fisiopatologia da DP associada ao DM: produção de produtos de glicosilação avançada, deficiente resposta imune, herança de determinados polimorfismos genéticos, alterações dos vasos sanguíneos, tecido conjuntivo e composição salivar. $\mathrm{Na}$ fase inicial predominam a gengivite e periodontite. Se não detectados precocemente, esses problemas podem evoluir para doença periodontal avançada. Puberdade, maior duração da doença, mau controle metabólico e higiene bucal inadequada são fatores que contribuem para progressão e agressividade da DP. Conclusão: O melhor conhecimento dos mecanismos envolvidos na fisiopatogenia da DP associada ao DM auxiliará na instituição de medidas preventivas e terapêuticas precoces. É importante que médicos e dentistas orientem os pacientes com DM sobre a necessidade de bom controle glicêmico e higiene bucal adequada para minimizar os riscos de doença periodontal. (Arq Bras Endocrinol Metab 2007;51/7:1050-1057)

Descritores: Diabetes melito; Doença periodontal; Periodontite

\section{ABSTRACT}

\section{Pathogenic Aspects of the Periodontal Disease Associated to Diabetes} Mellitus.

Objective: Systematic review of present knowledge about the association between diabetes mellitus (DM) and periodontal disease (PD) with emphasis on their physiopathogenesis. Data sources: Bibliographic search through MEDLINE and LILACS databases, in the last five years, using the following descriptors: "diabetes mellitus", "periodontal disease", and "periodontitis". Summary of data: Periodontal tissues are the oral structures most affected by DM. DM predisposes to the development of PD, which leads to loss of glycemic control, which emphasizes the importance of the two-way relationship between these two diseases. Several mechanisms are involved in the physiopathology of PD associated with DM: production of advanced glycosilation products, deficient immune response, inheritance of certain genetic polymorphisms, alterations in blood vessels, conjunctive tissue and salivary composition. In the initial phase, gingivitis and periodontitis predominate. If not detected early, these problems can develop into advanced periodontal disease. Puberty, with its hormonal alterations, longer duration of the disease, poor metabolic control and inadequate oral hygiene are factors that contribute to PD progression and aggressiveness. Conclusion: Better knowledge about the mechanisms involved in the physiopathogenesis of PD associated with DM would help to institute early preventive and therapeutic measures. It is important for doctors and dentists to instruct their patients with DM about the need for good glycemic control and adequate oral hygiene, to minimize the risks for the appearance of periodontal disease and consequent loss of glycemic control. (Arq Bras Endocrinol Metab 2007;51/7:1050-1057)

Keywords: Diabetes mellitus; Periodontal disease; Periodontitis 
$\mathrm{D}$ IABETES MELITO (DM) É UMA doença crônica caracterizada por deficiência parcial ou total na produção de insulina ou por resistência à sua ação. Isso leva à anormalidade nos metabolismos glícidico, protéico e lipídico, que resultam em hiperglicemia, a qual induz múltiplas anormalidades sistêmicas. Estimase que, em 2010, aproximadamente 221 milhões de pessoas serão portadoras de DM (1).

Além das complicações crônicas, como nefropatia, neuropatia e retinopatia, o DM também está relacionado a complicações bucais. A doença periodontal (DP) é a complicação oral mais importante, sendo considerada a sexta complicação clássica do diabetes (2). Essas doenças apresentam uma associação bidirecional na qual $O$ diabetes favorece o desenvolvimento da doença periodontal e esta, quando não tratada, piora o controle metabólico do diabetes (3). Além do seu efeito deletério sobre a saúde oral e controle glicêmico, vários estudos têm demonstrado associação da doença periodontal com a doença coronariana, outra importante causa de morbidade e mortalidade em diabéticos (4).

Tendo em vista a importância e gravidade desta complicação e as dúvidas relacionadas à sua patogênese, este trabalho tem por objetivo revisar os conhecimentos recentes e atualizar a classe médica sobre a fisiopatologia da doença periodontal associada ao diabetes melito.

\section{METODOLOGIA}

Foram pesquisados através dos bancos de dados MEDLINE (PubMed: Cumulative Index Medicus) e LILACS-BIREME (Literatura Latino-Americana e do Caribe em Ciências da Saúde), artigos científicos publicados nos últimos cinco anos que abordassem a patogenia da doença periodontal associada ao diabetes melito. $\mathrm{Na}$ pesquisa bibliográfica foram utilizados, em várias combinações, os seguintes termos de pesquisa (palavras-chaves e delimitadores): "diabetes mellitus", "periodontitis" e "periodontal disease".

A pesquisa bibliográfica incluiu livros-textos de periodontia, consensos, editoriais, artigos de revisão e casocontrole escritos nas línguas inglesa, portuguesa ou espanhola. Os artigos de caso-controle poderiam ser incluídos desde que descrevessem adequadamente os critérios de seleção e cujos resultados permitissem avaliar a patogenia da doença periodontal associada ao DM.

\section{DENTE, PERIODONTO E DOENÇA PERIODONTAL}

O dente pode ser dividido, de forma didática, em uma porção externa denominada coroa e outra interna em- bebida no processo alveolar, a raiz (5). O osso alveolar, estrutura onde os dentes são alojados, é formado predominantemente por colágeno, sialoproteínas, osteopoetinas e proteoglicanos. A camada mais interna do dente, a polpa, contém os nervos e suprimento vascular. A próxima camada, a dentina, é um tecido mineralizado formado pela extensão dos odontoblastos e tecidos conectivos localizados na dentina. O esmalte é uma camada mineralizada que cobre a coroa. O cemento radicular é a substância que cobre a raiz do dente, sendo constituído por tecido conectivo semelhante ao osso. O ligamento periodontal fixa o dente ao processo alveolar, sendo formado por tecido fibroso, células epiteliais e células mesenquimais indiferenciadas. A gengiva, estrutura que cobre o processo alveolar e parte dos dentes é composta principalmente de colágeno, proteoglicanos, fibronectina, osteonectina e elastina. O espaço entre o dente e o epitélio gengival é denominado de sulco gengival, cuja profundidade é determinada pelo ligamento periodontal. A principal função do periodonto (formado pelo cemento radicular, osso alveolar, gengiva e ligamento periodontal) é apoiar os dentes e suportar as forças de oclusão (figura 1).

A doença periodontal é o processo inflamatório que ocorre na gengiva em resposta a antígenos bacterianos da placa dentária que se acumulam ao longo da margem gengival. A placa é um biofilme constituído por bactérias, proteínas salivares e células epiteliais descamadas (5). Sua manifestação inicial é a gengivite, caracterizada por hiperemia, edema, recessão e sangramento gengival (figura 2). Se não tratada precocemente, ela pode evoluir para periodontite (figura 3). Uma das primeiras alterações clínicas causadas pela periodontite é a perda de inserção dos tecidos periodontais que suportam e protegem o elemento dental com formação da bolsa gengival. Com a superfície dentária livre do epitélio protetor, ocorre acúmulo de placa bacteriana e destruição dos tecidos pela proliferação de microorganismos patogênicos (6). A doença periodontal grave afeta estruturas mais profundas, causando reabsorção das fibras colágenas do ligamento periodontal, reabsorção do osso alveolar, abscessos, aumento da profundidade das bolsas, maior mobilidade dentária e perda de dentes (7).

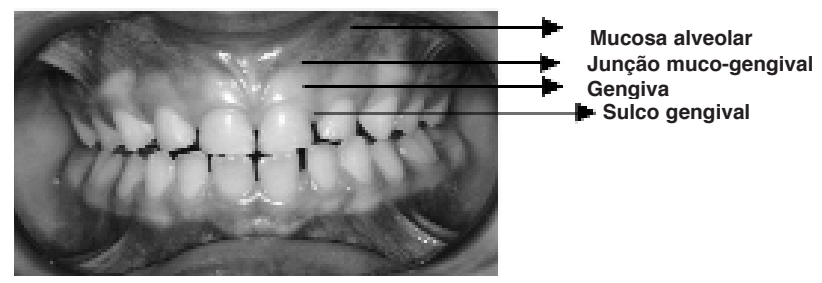

Figura 1. Aspectos anatômicos do peridonto. 


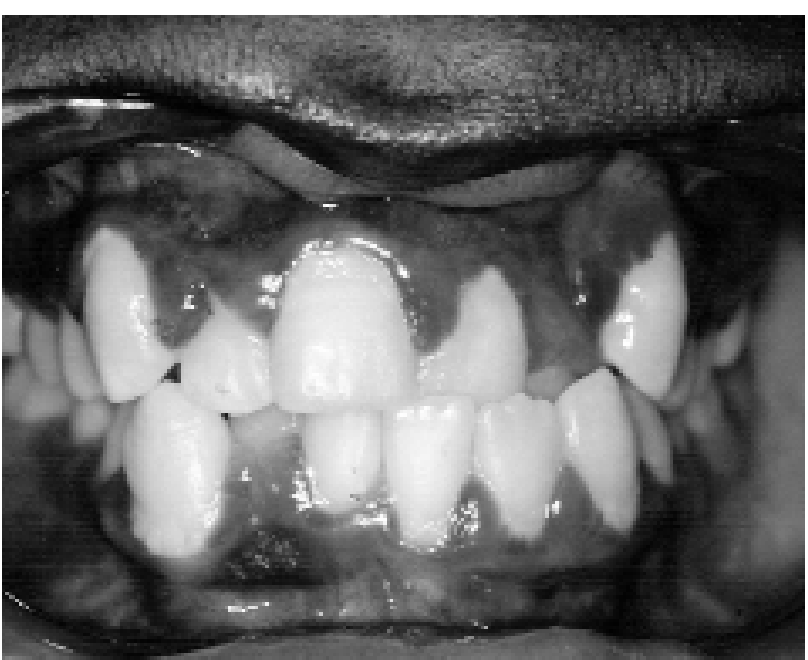

Figura 2. Gengivite em adolescente.

\section{PATOGENIA DA DOENCAA PERIODONTAL ASSOCIADA AO DIABETES}

Diversos fatores associados ao DM podem influenciar a progressão e agressividade da doença periodontal: tipo de diabetes (mais extensa em diabetes melito tipo 1), idade do paciente (aumento do risco durante e após a puberdade), maior duração da doença e controle metabólico inadequado $(3,8)$.

Uma vez que a microbiota periodontal em pacientes com DM é similar à de não-diabéticos (bactérias gram-negativas anaeróbicas como Actinobacillus, Bacteróides e Porphyromonas) (5), outros fatores, tais como hiperglicemia e anormalidades da resposta imune do hospedeiro frente às infecções bucais, parecem ser os responsáveis pela maior prevalência desta complicação em diabéticos $(9,10)$.

A figura 4 ilustra os principais mecanismos patogênicos da DP associada ao DM, os quais serão discutidos a seguir.

\section{ALTERAÇões BIOQUÍMICAS}

\section{Aumento da glicação não enzimática}

Os produtos finais da glicação e oxidação não enzimática de proteínas e lipídeos (AGEs - advanced glycation end products) e a interação com seus receptores (RAGEs - receptor for advanced glycation end products), imunoglobulinas presentes na superfície de algumas células com fibroblastos, macrófagos, células do endotélio vascular e do tecido periodontal, são considerados um dos grandes responsáveis pelas

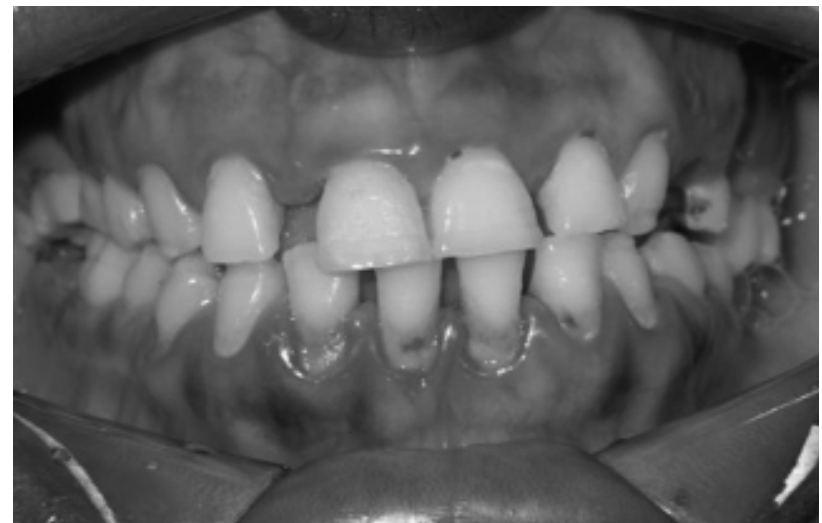

Figura 3. Periodontite avançada.

complicações crônicas (por ex. nefropatia, retinopatia, neuropatia) em pacientes diabéticos (9-11).

Carboidratos aldeídicos ou cetônicos, a exemplo da glicose e frutose, reagem não-enzimaticamente com grupos amínicos livres encontrados em proteínas, para formarem aldiminas e cetiminas, conhecidas como bases de Schiff ou compostos de Maillard. Essas bases são os primeiros compostos a serem formados na reação de glicação e são instáveis. No entanto, períodos longos de glicemia elevada e, sobretudo, se as proteínas utilizadas na glicação pertencerem a estruturas de longa duração (por ex. colágeno, cristalino, mielina, elastina, mioglobina, hemoglobina, lipoproteínas de baixa densidade) fazem com que os complexos de Maillard sofram modificações para ceto-aminas secundárias, conhecidas como arranjos moleculares de Amadori, que os tornam mais estáveis, porém quimicamente reversíveis (11). As condições que originam esses complexos, quando mantidas, permitem o acúmulo dos AGEs, que por serem moléculas estáveis não se degradam mesmo quando os níveis de glicemia retornam à normalidade (13). Pele, rins, artérias, capilares e proteínas do sangue são os principais locais de depósito dos AGEs.

A formação dos AGEs está relacionada ao tempo em que o organismo ficou exposto à hiperglicemia. Portanto, quanto maior a duração do diabetes e pior o controle glicêmico, maior será a quantidade desses produtos circulando e acumulados nos tecidos periodontais (14). O controle da glicemia provavelmente é uma das poucas, se não a única, maneira de reduzir a formação dos AGEs (13).

A associação dos AGEs com seus receptores (RAGEs) estimula a produção excessiva, por macró- 


\section{DIABETES}

MELITO

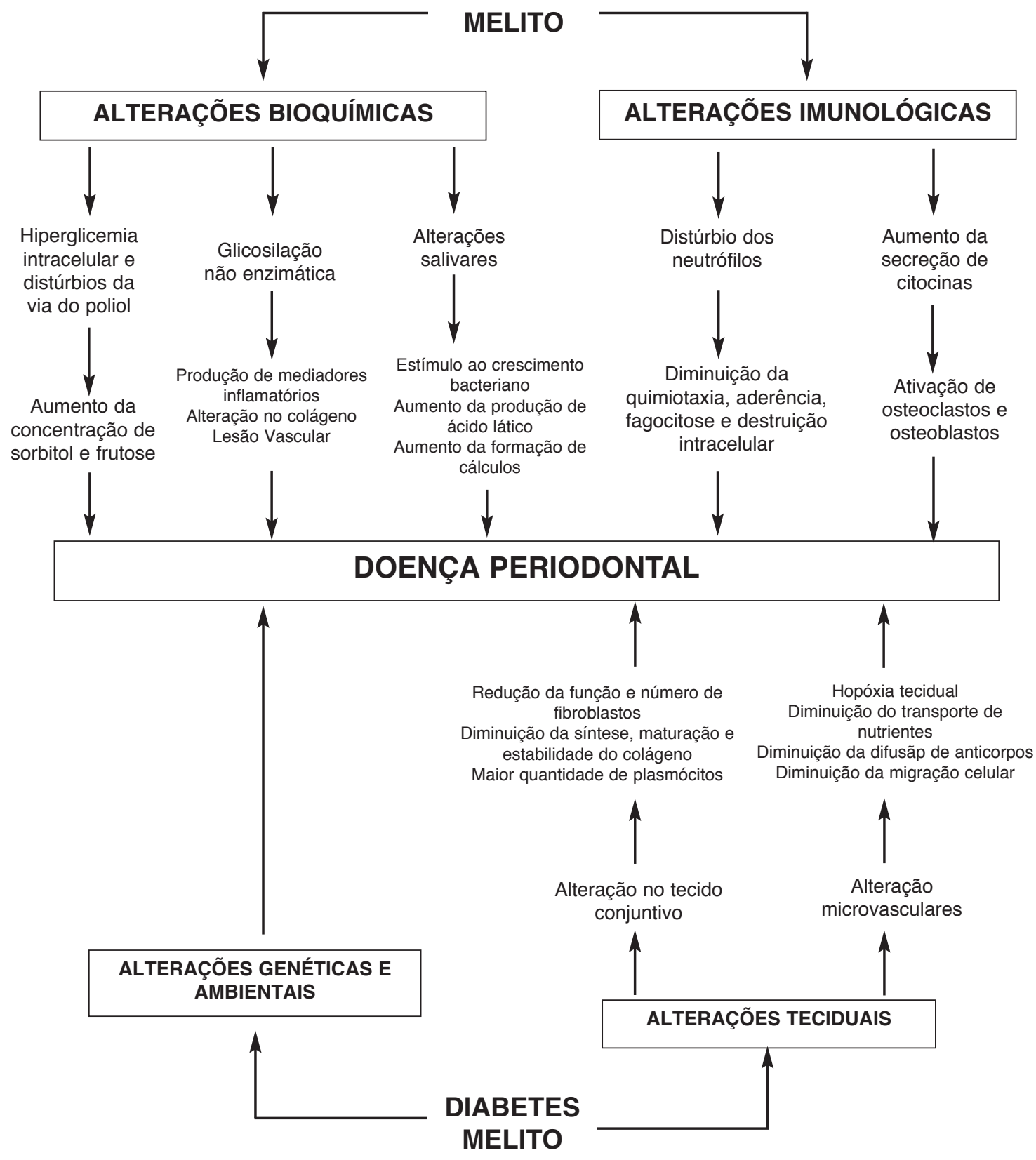

Figura 4. Fisiopatologia da periodontopatia associada ao diabetes melito.

fagos, de mediadores inflamatórios como a interleucina 1 e 6 , fator de crescimento I, fator de necrose tumoral alfa, prostaglandina e fator estimulador de colônias dos granulócitos. Essas substâncias estimulam a transformação do colágeno em compostos menos solúveis, mais resistentes à ação de enzimas e menos flexíveis, o que contribui para a dificuldade de cica- trização encontrada em pacientes diabéticos (9). Elas também ativam osteoclastos e colagenases, conduzindo à destruição do osso e tecido conjuntivo, aumentando a progressão e severidade da doença periodontal $(9,12-16)$.

Simultaneamente, a infecção periodontal, condicionada por células fagocitárias com monócitos, po- 
de induzir a um estado crônico de resistência à insulina, contribuindo para o ciclo de hiperglicemia. O acúmulo dos AGEs aumenta a trilha clássica da destruição tecidual, resultando em doença periodontal mais grave e em maior dificuldade de controlar a glicemia do diabético (9).

O retardo na ocorrência dessas complicações pode ser alcançado com a diminuição da formação e acúmulo desses produtos através do melhor controle glicêmico (13). Além disso, muitas pesquisas estão sendo realizadas para encontrar um medicamento que seja capaz de inibir a formação e os efeitos dos AGEs nos tecidos. A aminoguanidina demonstrou eficácia na inibição do entrecruzamento ocasionado pelos AGEs e as proteínas do plasma e colágeno, retardando a evolução de lesões microvasculares encontradas na retina e glomérulos de animais diabéticos $(13,16)$.

\section{Hiperglicemia intracelular e distúrbios nas vias do poliol}

Em tecidos como nervos, cristalino, rins e vasos sangüíneos, as unidades celulares transportadoras de glicose independem da insulina. Nesses tecidos, a hiperglicemia resulta em aumento intracelular de glicose, que é então metabolizada pela aldose-redutase, sendo reduzida a sorbitol (um tipo de poliol) e depois a frutose (17). Os níveis acumulados de sorbitol e frutose provocam aumento da osmolaridade intracelular e influxo de água e, por fim, lesão celular osmótica.

Os níveis elevados de sorbitol associados a outros mecanismos como glicação não enzimática, lesão oxidativa e formação de imunocomplexos são alguns dos processos patogênicos desencadeadores da microangiopatia, hipoxia tecidual e vasodilatação, que levam à agressão dos tecidos periodontais (18).

\section{Alterações da saliva}

A saliva é o principal fator de defesa da boca. Alterações na sua qualidade e quantidade afetam a saúde oral. No DM, as principais alterações encontradas na saliva são hipossalivação e alteração da sua composição, principalmente aquelas relacionadas à elevação dos níveis de glicose, potássio, cálcio, magnésio, proteínas, alfa-amilase, IgA, IgG e maior atividade da peroxidase $(19,20)$.

A hipossalivação pode ocorrer como resultado de neuropatia autonômica, doença microvascular, hiperglicemia, uso de agentes hipoglicêmicos e pH ácido (21). Esse distúrbio é freqüente em pacientes diabéticos, podendo causar úlceras, queilites e língua fissurada (19). A xerostomia ou sensação de boca seca se diferencia da hipossalivação por não apresentar redução do fluxo salivar.
A maior quantidade de glicose na saliva e líquido gengival crevicular estimula o crescimento bacteriano, reduz a capacidade dos fibroblastos em promover a cicatrização e aumenta a produção de ácido lático, reduzindo o $\mathrm{pH}$ e diminuindo a atividade tampão da saliva, os quais são fatores de risco para cárie e doença periodontal (22).

O elevado teor de cálcio na saliva predispõe à formação de cálculo e fatores irritativos nos tecidos periodontais (22). O aumento da atividade do sistema peroxidase salivar (SPS) pode contribuir para o desenvolvimento de gengivite através do exsudato de leucócitos no fluido crevicular gengival (21). Juntos, esses mecanismos contribuem para um maior risco de doença periodontal.

\section{ALTERAÇÕES IMUNOLÓGICAS}

Indivíduos com deficiente resposta imune não conseguem eliminar os microorganismos patogênicos, perpetuando o processo inflamatório. A inflamação crônica produz radicais livres de oxigênio que ativam metaloproteinases, que degradam o colágeno do ligamento periodontal diminuindo a fixação do dente ao processo alveolar e aumentando a profundidade do sulco gengival (5).

\section{Distúrbios dos neutrófilos}

Em diabéticos, a atividade dos neutrófilos polimorfonucleares está modificada devido à diminuição da quimiotaxia, aderência, fagocitose e destruição intracelular, o que diminui a capacidade imunológica e a resposta inflamatória desses pacientes $(22,23)$. Estas alterações são causadas, em parte, pela hiperglicemia e acúmulo de AGEs, que provocam ativação contínua dos polimorfonucleares (resposta hiper-inflamatória) com ativação espontânea da cadeia oxidativa e liberação da mieloperoxidase, elastase e outros elementos dos grânulos neutrofílicos (22).

\section{Secreção de citocinas e mediadores inflamatórios versus lipopolissacarídeos}

Diabéticos apresentam níveis séricos e salivares de interleucina-1 (IL-1), fator de necrose tumoral alfa (TNF- $\alpha)$ e prostaglandina E2 $\left(\mathrm{PGE}_{2}\right)$ mais elevados do que não-diabéticos. Graves \& Cochran relataram associação da IL-1 com a perda de inserção conjuntiva e reabsorção óssea alveolar (24). A IL-6 também está aumentada na DP e pode estar envolvida na patogênese da retinopatia diabética (25). O TNF- $\alpha$, produzido por macrófagos ativados por bactérias gram- 
negativas, induz a expressão de prostaglandinas, estimula a produção de enzimas líticas como as metaloproteinases e limita o reparo celular através da indução da apoptose de células produtoras da matriz (14). Outra ação do TNF- $\alpha$ seria a indução de resistência insulínica com piora do controle metabólico do DM (25). Wright e cols. relatam que o TGF $\beta$ (tumor growth factor beta) estimula a produção de componentes da matriz extracelular por fibroblastos, função essencial para a regeneração dos tecidos periodontais (27). A $\mathrm{PGE}_{2}$ induz a vasodilatação, aumento da permeabilidade vascular e estimula a síntese de metaloproteinases (degradam a matriz extracelular tecidual), levando à destruição de tecido conjuntivo. $\mathrm{A} \mathrm{PGE}_{2}$ também atua no tecido ósseo induzindo a síntese de colagenase por osteoblastos, favorecendo o início da reabsorção óssea alveolar. Acredita-se, também, que as prostaglandinas sensibilizem as células ósseas a outros mediadores químicos, contribuindo indiretamente na reabsorção óssea. Estudos realizados em cachorros Beagles concluem que a suspensão da $\mathrm{PGE}_{2}$, por intermédio de drogas que atuam na sua síntese, diminui sensivelmente a perda de inserção conjuntiva e a reabsorção óssea alveolar, atenuando, dessa forma, a progressão da doença periodontal (28).

\section{ALTERAÇÕES GENÉTICAS E AMBIENTAIS}

Alterações genéticas podem aumentar a probabilidade de desenvolvimento do DM e doença periodontal (29).

Os genes responsáveis pela susceptibilidade genética ao DMl estão localizados em pelo menos 20 loci, denominados IDDM 1-15 (30). O IDDM 1 corresponde aos antígenos do sistema de histocompatibilidade humano (HLA). Nessa região, existem alelos que aumentam (ex. HLA-DQA1*0301, $-D Q B 1 * 0302) \mathrm{e}$ outros que diminuem (ex. HLA-DQABI*0602) o risco de evolução para DMl (31). Além deles, os genes que controlam a síntese da interleucina (IL-1), TNF- $\alpha$ e fibrinogênio estão envolvidos na susceptibilidade à infecção periodontal (7). Os imunorreceptores, em particular o receptor $\mathrm{Fc}$ I $\gamma \mathrm{G}(\mathrm{Fc}$ gamaR, $\mathrm{FcYr}$, este último expresso na superfície celular das células $\mathrm{NK}$, macrófagos, linfócitos $\mathrm{T}$ e monócitos), a depender da alteração genética podem levar a uma maior agressividade e formas crônicas da periodontite (32).

Desde que a DP passou a ser reconhecida como doença eco-genética, deve-se considerar também o efeito de fatores externos como alterações locais e uso de medicamentos que causam impacto na estrutura do tecido conjuntivo periodontal e na gengiva (33).

\section{ALTERAÇÕES TECIDUAIS}

Em pacientes diabéticos, as alterações do tecido conjuntivo e vascular prejudicam a cicatrização dos tecidos normais, propiciando o desenvolvimento de doença periodontal.

\section{Alterações do tecido conjuntivo}

O tecido conjuntivo dos diabéticos tem seu metabolismo comprometido devido à redução da função e número de fibroblastos, menor síntese, maturação e estabilidade do colágeno, e maior quantidade de plasmócitos (19).

As características funcionais de diversas moléculas da matriz extracelular são alteradas pela ação dos AGEs. O colágeno foi a primeira proteína em que se observou a presença de ligações intermoleculares covalentes produzidas pelos AGEs (16). O menos sensível à degradação enzimática é o colágeno glicosilado. Isso dificulta uma cicatrização normal do tecido danificado, o qual é observado com colágeno tipo IV proveniente da membrana basal glomerular quando exposta à ação das metaloproteinases (13). A formação de AGEs no colágeno tipo IV na membrana basal dificulta a associação lateral dessas moléculas em uma estrutura tridimensional complexa que gera reticulação das fibras de forma anárquica, causando aumento da permeabilidade (16). No colágeno tipo I, a agregação molecular resultante induz certa distorção da estrutura molecular da fibrila (16).

O fator de crescimento de fibroblastos (FGF) tem a expressão do seu fator básico alterada nos pacientes diabéticos devido aos altos níveis de glicose, gerando inibição do crescimento das células do ligamento periodontal (9). A fibronectina (sinalizador para as células do ligamento periodontal entre o meio intra e extracelular) sofre alterações devido aos elevados níveis de glicose, ocasionando mudanças morfológicas e morte das células desse ligamento; além disso, ocorre diminuição da resposta quimiotática das células do ligamento periodontal para o fator de crescimento derivado de plaquetas (PDGF) (9). Esse pode ser um dos fatores que levam à dificuldade de cicatrização em pacientes diabéticos e à causa da destruição mais grave na doença periodontal (9).

$\mathrm{O}$ aumento da profundidade do sulco gengival com formação de bolsas gengivais e diminuição da pressão de oxigênio $\left(\mathrm{PO}_{2}\right)$ contribui para proliferação bacteriana, resultando em piora da infecção e inflamação. Se houver comprometimento da circulação local, como será discutido no próximo tópico, pode ocorrer invasão bacteriana do ligamento periodontal (33). 


\section{Alterações microvasculares}

A hiperglicemia modifica o balanço metabólico promovendo diversas alterações nos tecidos vasculares. Dentre estas alterações destacam-se: glicosilação das apoproteínas (responsáveis pela captação de lipídios potencialmente aterogênicos), glicosilação do colágeno da parede dos vasos, aumento da agregação plaquetária com maior risco de tromboembolismo, aumento da permeabilidade vascular, alteração da atividade da proteína quinase provocando insuficiência vascular periférica gerada pela proliferação das células musculares e acúmulo subendotelial de proteínas do plasma, como a albumina, lipoproteínas de baixa densidade (LDL) e imunoglobulina G (IgG) $(15,16,22,34)$.

Essas alterações que ocorrem no tecido vascular do diabético alteram a difusão do oxigênio, transporte de nutrientes, migração de polimorfonucleares e monócitos/macrófagos e a difusão de anticorpos, desencadeando desequilíbrio fisiológico que aumenta a susceptibilidade dos tecidos à doença periodontal (34).

\section{PERIODONTITE E DOENÇA CARDIOVASCULAR}

As doenças cardiovasculares (DCV), especialmente as cardiopatias coronarianas, resultam, mais freqüentemente, da aterosclerose. Seu desenvolvimento está relacionado a vários fatores de risco como idade, sexo, hipertensão, tabagismo, dislipidemia, história familiar de DCV, sedentarismo e diabetes. Além desses, uma variedade de fatores inflamatórios e hemostáticos são associados ao maior risco de DCV: níveis elevados da proteína $\mathrm{C}$ reativa (PCR), fator de von Willebrand, interleucina-6 (IL-6), fator de necrose tumoral alfa (TNFa) e fibrinogênio (35).

Mais recentemente, tem-se estudado a associação da doença periodontal como fator de risco para DCV com base nas seguintes teorias (35): (a) bactérias periodontopatogênicas (Porphyromonas gingivalis, Bacteróides forsytus, Actinobacillus actinomycetemcomitans, Prevotela intermedia, Streptococus sanguis), identificadas nas lesões ateromatosas, poderiam atuar diretamente sobre a placa aterosclerótica predispondo à sua ruptura; (b) a bacteriemia resultante da periodontite poderia aumentar a atividade trombogênica a partir do aumento da viscosidade sangüínea e da produção de fatores estimuladores da agregação plaquetária. Corroborando esta hipótese, algumas cepas de Streptococus sanguis e Porphyromonas gingivalis expressam proteínas capazes de causar agregação plaquetária; e (c) a doença periodontal através da liberação de mediadores inflamatórios sistêmicos promoveria aumento de marcadores sabidamente associados ao maior risco de DCV, como a PCR e a IL-6.

Embora a doença periodontal esteja epidemiologicamente associada às doenças cardiovasculares decorrentes de aterosclerose, as bases desta associação ainda precisam ser melhor estudadas para elucidar a relação causal entre essas duas doenças. Os progressos nesta área do conhecimento serão ainda mais importantes para diabéticos que apresentam maior prevalência de doença cardiovascular e doença periodontal, e nos quais os patógenos da doença periodontal podem aumentar a resistência insulínica mediada por citocinas pró-inflamatórias, aumentando o risco de doença cardiovascular e de óbitos por doença renal $(14,36)$.

\section{CONCLUSÃo}

O diabetes melito está relacionado a diversas alterações que podem predispor à doença periodontal. Dentre elas, destacam-se as alterações bioquímicas, como produção de AGES, hiperglicemia intracelular gerando distúrbios nas vias do poliol, alterações na saliva, distúrbios imunológicos, como redução da função dos neutrófilos e aumento da produção de citocinas e mediadores inflamatórios, alterações genéticas que aumentam a probabilidade de desenvolvimento da doença periodontal e lesões teciduais, como comprometimento do metabolismo do colágeno, aumento da permeabilidade vascular e espessamento da membrana basal capilar.

Os AGEs parecem ser um dos principais responsáveis pelas alterações que levam à doença periodontal, pois estão relacionados à diminuição da eficiência dos neutrófilos, aumento da destruição dos tecidos conjuntivo e ósseo, danos vasculares e produção exagerada de mediadores inflamatórios.

\section{AGRADECIMENTOS}

Este trabalho foi parcialmente financiado pela Fundação de Amparo à Pesquisa do Estado da Bahia (FAPESB).

\section{REFERÊNCIAS}

1. Amos AF, MacCarty DJ, Zimmet $P$. The rising global burden of diabetes and its complications: estimates and projections to 2010. Diabet Med 1997;14(suppl 5):S1-5. 
2. Kawamura JY. Avaliação clínica, radiográfica e imunohistoquímica da doença periodontal em pacientes portadores de diabetes mellitus tipo 1. [Dissertação de mestrado]. São Paulo: Universidade de São Paulo, 2002.

3. Wehba C, Rodrigues AS, Soares FP. Diabetes e doença periodontal: uma relação bidirecional. In: Brunette CM. Periodontia Médica: Uma abordagem integrada. São Paulo: Senac, 2004. pp. 172-95.

4. Beck JD, Slade G, Offenbacher S. Oral disease, cardiovascular disease and systemic inflamation. Periodontol 2000 2000;23:110-20.

5. Herring ME, Shah SK. Periodontal disease and control of diabetes mellitus. J Am Osteopath Assoc 2006;106:416-21.

6. Nanci A, Bosshartdt DD. Structure of periodontal tissues in health and disease. Periodontol 2000 2006;40:11-28.

7. Scannapieco FA. Inflamação periodontal: da gengivite à doença sistêmica? Compendium 2004;25(7):16-25

8. Marin PN, Rodriguez LJ, Guillén PJA, Castillo VJF, Sierra HFG. Efecto del control metabólico en pacientes diabéticos tipo 1 y su asociación con enfermedad periodontal. Rev Invest Clin 2002;54(3):218-25.

9. Greghi SLA, Brito MCT, Oliveira MR, Guimarães MCM. Relação entre diabetes mellitus e doença periodontal. Rev APCD 2002;56(4):265-9.

10. Vernillo AT. Dental considerations for the treatment of patients with diabetes mellitus. JADA 2003:134:24S-33S

11. Jakus V, Rietbrock N. Advanced glycation end-products and the progress of diabetic vascular complications. Physiol Res 2004;53:131-42.

12. Rodrigues, LEA. Glicosilação de proteínas como importante fator no desenvolvimento das complicações do diabetes. Boletim da SBEM 2001;3:23-34

13. Rivas MA, Horta OD. Productos de la glucosilación avanzada y diabetes mellitus. Rev Cubana End 1999;10(1):57-64.

14. Southerland JH, Taylor GW, Moss K, Beck JD, Offenbacher S. Commonality in chronic inflammatory diseases: periodontitis, diabetes and coronary artery disease. Periodontol 2000 2006;40:130-43.

15. Antunes SF, Graça AM, Nurkin LN, Oliveira BR. Diabetes mellitus e a doença periodontal. Rev Odonto Cienc 2003;18(40):107-11.

16. Gugliucci A. Glicación de proteínas: rol protagónico de la hiperglicemia en las complicaciones crónicas de la diabetes mellitus. Rev Med Uruguay 2000;16:58-75.

17. Crawford JM, Cotran RS. Pâncreas. In: Robbins. Patologia estrutural e funcional. Rio de Janeiro: Guanabara Koogan, 2000. pp. 809-33.

18. lughetti L, Marino R, Bertolani F, Bernasconi S. Oral health in children and adolescents with IDDM - a review. J Pediatr Endocrinol Metab 1999;12:603-10.

19. Ferreira SRG, Vannucci MG. Noções de diabetes mellitus para o não especialista. In: Brunette CM. Periodontia Médica: Uma abordagem integrada. São Paulo: Editora Senac, 2004. pp. 150-70.

20. López ME, Colloca ME, Paez RG, Schallmach JN, Koss MA, Chervonagura A. Salivary characteristics of diabetic children. Braz Dent J 2003;14(1):26-31.

21. Aren G, Sepet E, Özdemir D, Dinççag N, Güvener B, Firatli E. Periodontal health, salivary status, and metabolic control in children with type 1 diabetes mellitus. J Periodontol 2003;74:1789-95.
22. Sousa RR, Castro RD, Monteiro $\mathrm{CH}$, Silva SC, Nunes AB. O paciente odontológico portador de diabetes mellitus: uma revisão de literatura. Pesq Bras Odontoped Clin Integr 2003;3(2):71-7.

23. Alves RD, Godoy GP, Figueiredo CRLV, Pinto LP. Mecanismos imunológicos e auto-imunidade na doença periodontal. Rev Oonto Cienc 2003;18(40):138-42.

24. Graves DT, Cochran D. The contribution of interleukin-1 and tumor necrosis factor to periodontal tissue destruction. $\mathbf{J}$ Periodontol 2003;74(3):391-401.

25. Noma H, Sakamotol, Mochizuki H, Tsukamoto $H$, Minamoto A, Funatsu $\mathrm{H}$, et al. Relationship between periodontal disease and diabetic retinopathy. Diabetes Care 2004;27:615.

26. Nishimura F, Iwamoto $Y$, Mineshiba J, Shimizu A, Soga $Y$, Murayama Y. Periodontal disease and diabetes mellitus: the role of tumor necrosis factor alpha in a 2 -way relationship. $\mathbf{J}$ Periodontol 2003;74:97-102.

27. Wright HJ, Chapple IL, Matthews JB. Levels of TGF $\beta 1$ in gingival crevicular fluid during a 21-day experimental model of gingivitis. Oral Dis 2003;9(2):88-94.

28. Paquette DW, Williams RC. Modulation of host inflammatory mediators as treatment strategy for periodontal diseases. Periodontol 2000 2000;24:239-52.

29. Kinane DF, Shiba H, Hart TC. The genetic basis of periodontitis. Periodontol 2000 2005;39:91-117.

30. Melo MB. Diabetes mellitus. In: Monte O, Longui CA, Calliari LE, Kochi C. Endocrinologia para o Pediatra. 3a ed. São Paulo: Atheneu, 2006. pp. 883-6.

31. Alves C, Meyer I, Toralles MB, Lemaire D. Distribuição e freqüência de haplótipos HLA em brasileiros com diabetes melito tipo 1. Arq Bras Endocrinol Metab 2006;50:366-44.

32. Takashiba S, Naruishi K. Gene polymorphism in periodontal health and disease. Periodontol 2000 2006;40:94-106.

33. Bartold PM, Narayanan AS. Molecular and cell biology of healthy and diseased periodontal tissues. Periodontol 2000 2006;40:29-49.

34. Palmer R, Soory M. Fatores modificadores: diabetes, puberdade, gravidez e menopausa e tabagismo. In: Lindhe J. Tratado de periodontia clínica e implantologia oral. $4^{\mathrm{a}}$ ed. Rio de Janeiro: Guanabara Koogan, 2005. pp. 176-80.

35. Dalla Costa T, Silva Jr GFS, Terezan MLF. Influência das doenças periodontais sobre as cardiopatias congênitas. Rev Cien Med Biol (Salvador) 2005:4:63-9.

36. Rech RL, Nurkin N, Cruz I, Sostizzo F, Baião C, Perrone JA, et al. Associação entre doença periodontal e síndrome coronariana aguda. Arq Bras Cardiol 2007;88:185-90.

Endereço para correspondência:

Crésio Alves

Rua Plínio Moscoso 222/601

40157-190 Salvador, BA

E-mail: cresio.alves@uol.com.br 